\title{
Fibrillar Templating of Hydrotalcites
}

\author{
Alicia E. Sommer ${ }^{1}$, Geolar Fetter ${ }^{1, *}$ and Pedro Bosch ${ }^{2}$ \\ ${ }^{1}$ Universidad Autónoma de Puebla, Facultad de Ciencias Químicas, Blvd. 14 Sur y Av. San Claudio, 72570 Puebla, \\ PUE, Mexico and ${ }^{2}$ Universidad Nacional Autónoma de México, Instituto de Investigaciones en Materiales, Ciudad Uni- \\ versitaria, 04510 México, D. F., Mexico
}

\begin{abstract}
Layered double hydroxides also known as hydrotalcites have been synthesized in presence of fibrillar organic materials: human hair, cotton or nylon. These templates differ on their diameter, hydrophobicity and surface roughness. These parameters are correlated to the morphology and texture of the resulting hydrotalcites. A rapid synthesis method based on microwave irradiation is used and the materials were characterized by complementary physical techniques.
\end{abstract}

Key Words: Human hair, cotton, nylon, layered double hydroxides, microwave irradiation.

\section{INTRODUCTION}

Layered double hydroxides (LDH's), hydrotalcite-like compounds or hydrotalcites are anionic clays as they have positively charged layers, due to a partial substitution of a divalent metal by a trivalent one. They may be used in catalysis, adsorption or ion exchange, among others [1-3]. These materials can be represented by the general formula $\left[\mathrm{M}^{2+}{ }_{1-\mathrm{x}} \mathrm{M}^{3+}{ }_{\mathrm{x}}(\mathrm{OH})_{2}\right]\left(\mathrm{A}^{\mathrm{m}-}\right)_{\mathrm{x} / \mathrm{m}} \cdot \mathrm{nH}_{2} \mathrm{O}$ where $\mathrm{M}^{2+}$ and $\mathrm{M}^{3+}$ are diand trivalent metal cations, respectively, and $\mathrm{A}^{\mathrm{m}-}$ is a compensating anion intercalated between layers $[4,5]$. Although it is possible to obtain various LDH's modifying the composition and the synthesis process, the most naturally occurring $\mathrm{LDH}$ is $\mathrm{Mg}_{6} \mathrm{Al}_{2}(\mathrm{OH})_{16} \mathrm{CO}_{3} .4 \mathrm{H}_{2} \mathrm{O}$. The usual synthesis procedure is co-precipitation of the cationic metals in a basic medium, followed by a hydrothermal treatment $[6,7]$. Some authors have reported recently on the use of templates to modify morphology and hence texture [8,9]. Those inducing agents are gas or alcohol molecules; in this case a vesicular shape is obtained. However, no other than globular or layered morphology has been reported. The particle shape is determinant if species as DNA [10], pigments [11] or polymers [12] have to be incorporated into a clay; a layered compound with a globular shape should not behave in the same way as a cylindrical one. Such features are crucial if hydrotalcites should be used as drug deliverers [3].

In this work we report on the effect of human hair, nylon and cotton used as templates in the hydrotalcite synthesis, in presence of microwave irradiation. Microwave irradiation, indeed, propitiates a rapid crystallization, a small crystallite size and the required equipment is rather simple [13-17]. The aim is to determine the effect of various cylindrical templates (hair, nylon or cotton) on the particle hydrotalcite morphology. The templates were chosen as a function of their size as well as their surface features.

*Address correspondence to this author at the Universidad Autónoma de Puebla, Facultad de Ciencias Químicas, Blvd. 14 Sur y Av. San Claudio, C.P. 72570 Puebla, PUE, Mexico; Fax: (52)2222443106;

E-mail: geolarfetter@yahoo.com.mx

\section{EXPERIMENTAL METHODS}

\section{Hydrotalcite Synthesis}

$\mathrm{Mg} / \mathrm{Al}$-hydrotalcite samples were synthesized from a $\mathrm{Mg}\left(\mathrm{NO}_{3}\right)_{2} \cdot 6 \mathrm{H}_{2} \mathrm{O}$ and $\mathrm{Al}\left(\mathrm{NO}_{3}\right)_{3} \cdot 9 \mathrm{H}_{2} \mathrm{O}$ (both from Aldrich) water solution $(1 \mathrm{M})$, a $0.5 \mathrm{M} \mathrm{NaOH}$ (Baker) aqueous solution and three different templates. Organic templates were human hair, cotton or nylon fibers.

Over a Becker recipient containing $2 \mathrm{~g}$ of template and enough $\mathrm{NaOH}$ solution to reach a $\mathrm{pH}$ value of 8 (even if this is not the usual value to synthesize hydrotalcites), the $\mathrm{Mg}-\mathrm{Al}$ solution was added, dropwise. The $\mathrm{pH}$ value was maintained constant $(\mathrm{pH}=8)$ adding the required amount of $\mathrm{NaOH}$ solution, as at higher $\mathrm{pH}$ values the templates decompose and agglomerate, and at lower $\mathrm{pH}$ values, the hydrotalcite does not precipitate. The resulting solution amounts correspond to a molar ratio $\mathrm{Mg} / \mathrm{Al}$ of 3 . The solution was continuously stirred.

After precipitation, the resulting gels were hydrothermally treated in a microwave autoclave (MIC-I, Sistemas y Equipos de Vidrio S.A. de C.V.) for 10 minutes at $80{ }^{\circ} \mathrm{C}$, operating at $2.45 \mathrm{GHz}$ and a power of $200 \mathrm{~W}$. The solids were recovered by decantation and washed several times with distilled water. The solids were, then, dried in an oven at $70{ }^{\circ} \mathrm{C}$ overnight.

The samples were labeled H-MW, C-MW and N-MW depending on the used template: hair, cotton or nylon, respectively. Lastly, a reference sample, R-MW, was prepared in the same way, without template and under microwave irradiation.

\section{Characterization}

\section{X-Ray Diffraction}

A Bruker-axs D8-advance diffractometer coupled to a copper anode X-ray tube was used to identify the compounds present in the powdered samples. A diffracted beam monochromator selected the $\mathrm{K} \alpha$ radiation. 


\section{FTIR Spectroscopy}

FTIR spectra in the region $4000-400 \mathrm{~cm}^{-1}$ were obtained with a Magna-IR Spectrometer 550 Nicolet. The pellets were prepared with $\mathrm{KBr}$.

\section{Nitrogen Adsorption}

The BET surface areas were determined from the nitrogen adsorption-desorption curves by the conventional multipoint technique with a Micromeritics ASAP 2020. The pore size distribution curves were obtained with the BJH method applied to the desorption branch. The samples were pretreated at $200{ }^{\circ} \mathrm{C}$ for 10 hours at high vacuum.

\section{Scanning Electron Microscopy}

A scanning electron microscope LEICA, Stereoscan 440 was used. The samples were previously covered with gold to avoid charge problems.

\section{RESULTS}

\section{X-Ray Diffraction}

Fig. (1) compares the X-ray diffraction patterns of the synthesized compounds. The R-MW sample diffractogram presents some broad and some sharp and intense peaks. The first ones correspond to hydrotalcite (JCPDS card 22700) whereas the second to nitratine (JCPDS card 361474). The nitratine precipitation is induced by the low $\mathrm{OH}$ concentration as $\mathrm{pH}$ value is 8 .

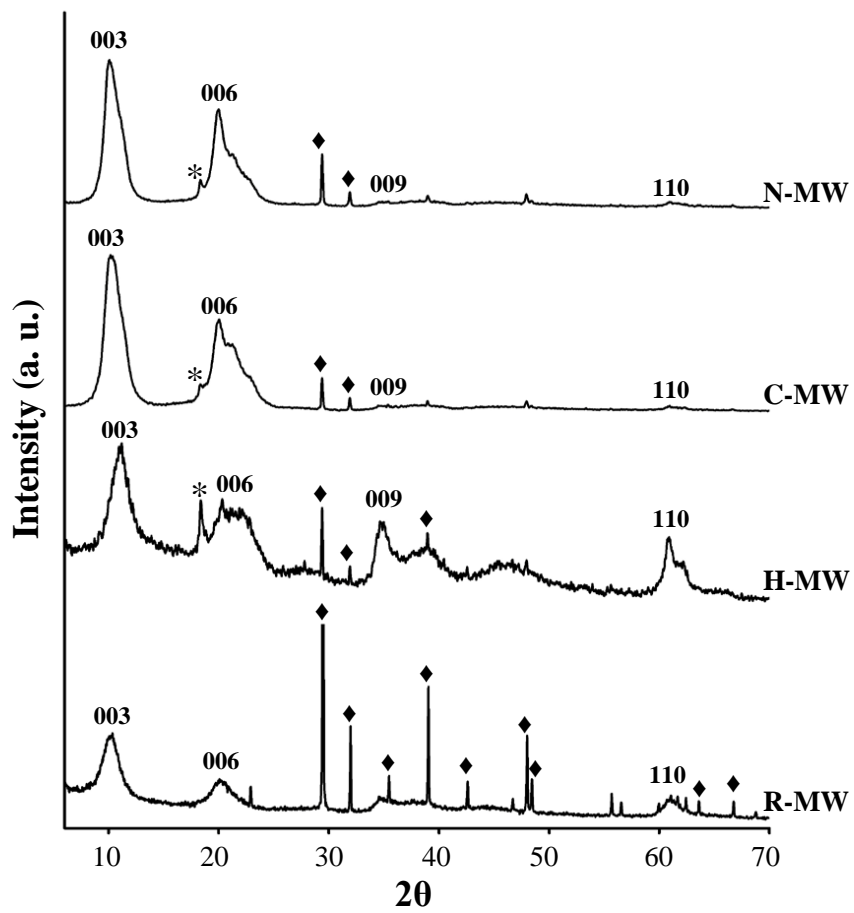

Fig (1). X-ray diffraction patterns of the samples: hydrotalcite synthesized without template (sample R-MW), synthesis in presence of hair (H-MW), C-MW in presence of cotton and N-MW in presence of nylon. The Miller indices correspond to hydrotalcite, *to gibbsite and $\bullet$ to nitratine.

In presence of hair, the obtained compound is again hydrotalcite; the amount of nitratine is now much lower. A third compound appears identified as gibbsite, $\mathrm{Al}(\mathrm{OH})_{3}$, JCPDS card 3318. If the fibers are cotton or nylon, again hydrotalcite is obtained with very small amounts of nitratine and gibbsite. In these two diffraction patterns, only the peaks 003 and 006 are evident. The 110 and 113 peaks have faded showing that order in the (a x b) plane is low, thus the arrangement of $\mathrm{Mg}$ and $\mathrm{Al}$ octahedra is not regular. Furthermore, as only the 003 and 006 peaks are present and not the 009 neither the 015 , the stacking order should be very short.

The interlayer distance obtained from the 003 peak position turned out to be $8.7 \AA$ in all samples. Thus, the compensating anions are nitrates as expected.

\section{Infrared Spectroscopy}

In all samples, the band at $3450 \mathrm{~cm}^{-1}$ is attributed to the $\mathrm{OH}$ structural groups and the band at $1657 \mathrm{~cm}^{-1}$ to water hydroxyls in hydrotalcites. ${ }^{1}$ The intense band at $1387 \mathrm{~cm}^{-1}$ is due to interlayered nitrates $[18,19]$. Hence, the infrared spectra, Fig. (2), present the typical profile of a double layered hydroxide intercalated with nitrates. Note that in $\mathrm{H}-\mathrm{MW}$ and $\mathrm{N}-\mathrm{MW}$ samples, bands at 1800 and $1500 \mathrm{~cm}^{-1}$ are not present, these bands are attributed to ammides and cheratin, therefore no residues of hair or nylon remain.

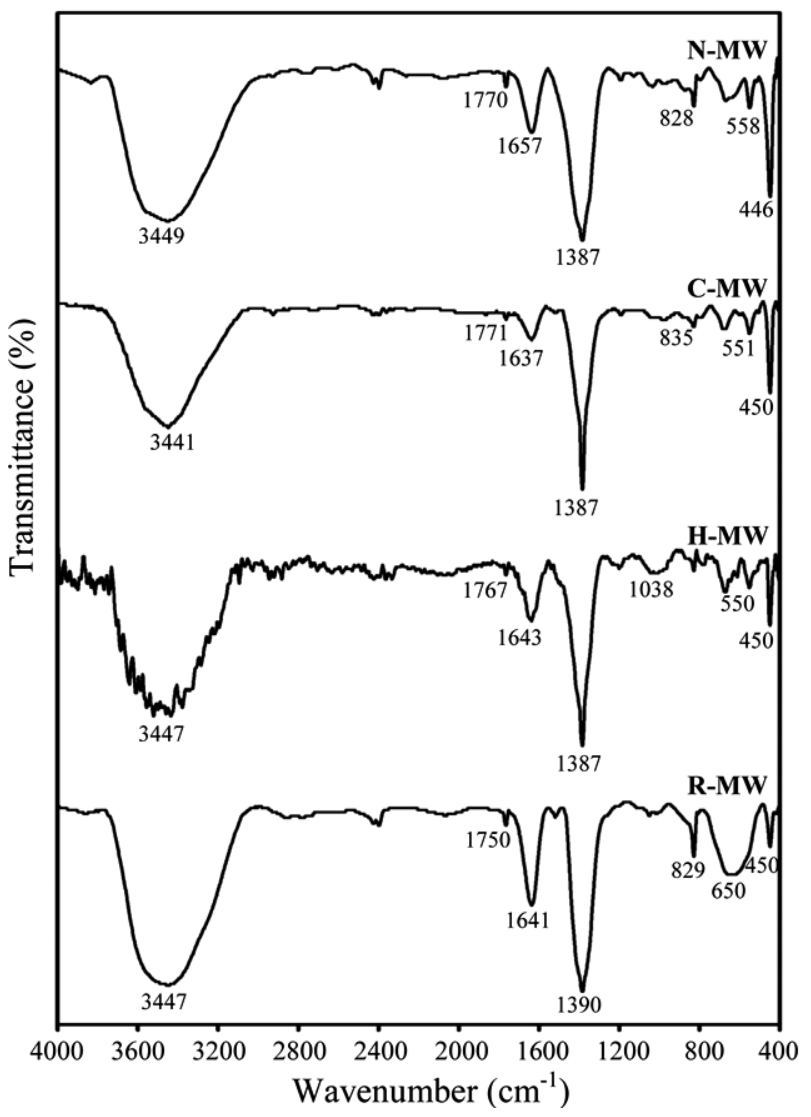

Fig. (2). Infrared spectra of the samples. The hydrotalcite synthesized without template is sample R-MW, the synthesis in presence of hair is $\mathrm{H}-\mathrm{MW}$, in presence of cotton it is C-MW and in presence of nylon N-MW. 


\section{Scanning Electron Microscopy}

\section{H-MW Sample Micrograph}

The hair cuticle originates from a single-layered epithelium and it is made up of a large number of overlapping scales of keratin. The separation between scales is 5 to 10 $\mu \mathrm{m}$. The epicuticle mainly made of fatty acid chains is a semi-permeable membrane which surrounds each cuticle cell and forms the outer surface of hair [20]. Human hair diameter depends on the person age and it oscillates between 90 and $70 \mu \mathrm{m}$.

The H-MW surface image obtained by SEM, Fig. (3), is homogeneous. It presents a series of ordered parallel sheets separated by a distance of 2 to $4 \mu \mathrm{m}$. They are densely stacked. On top, irregular particles $c a .2 \mu \mathrm{m}$ are dispersed all over, they probably correspond to the impurities already identified by X-ray diffraction.

\section{C-MW Sample Micrograph}

Cotton fiber is covered by a thin membrane or cuticle. The cotton fiber diameter is $c a .10-20 \mu \mathrm{m}$. Cotton fiber presents several key properties such as hydrophobicity, good affinity for hydrocarbons, rapid adsorption on contact, and high adsorption and retention through interfibre capillaries. The difference between cotton and hair is that cotton is a much thinner fiber (four times less) and that the surface is smooth. The corresponding micrograph, Fig. (4), shows a material composed by very large chunks (10 to $20 \mu \mathrm{m})$ which in turn are constituted by packed flakes, 1 to $5 \mu \mathrm{m}$ whose thickness is less than $0.1 \mu \mathrm{m}$.

\section{N-MW Sample Micrograph}

Nylon fibers are artificial polyamide polymers which are obtained from a diacid polycondensed with a diamine. The surface is smooth and presents more hydrophobic features than cotton. The fiber diameter is in this case close to $15 \mu \mathrm{m}$. In this sample, again, large globular particles are found ( $c a$. $4 \mu \mathrm{m}$, Fig. 5). The hydrotalcite flakes are stacked in a more disordered way as the layers cross each other.

\section{Nytrogen Physisorption}

Fig. (6) compares the adsorption-desorption cycles of RMW, H-MW, C-MW and N-MW samples. The curves are type IV and the hysteresis loops type B, following the IUPAC classification. Hence, pores are open at both extremes. The reference hydrotalcite, sample R-MW, differs from the three other materials. In this preparation the pore size distribution is narrow whereas in the other samples the distribution is very broad, mainly in the H-MW. The corresponding pore size distributions are shown in Fig. (7). The R-MW sample, whose surface area is $1 \mathrm{~m}^{2} / \mathrm{g}$, does not show any micropores. Hair, which is the larger template, generates a material whose pore size distribution is monomodal with a maximum at $30 \AA$; the surface area of this material is $8 \mathrm{~m}^{2} / \mathrm{g}$. The C-MW and N-MW preparations, whose surface areas are $5 \mathrm{~m}^{2} / \mathrm{g}$, present broad similar pore size distributions, from

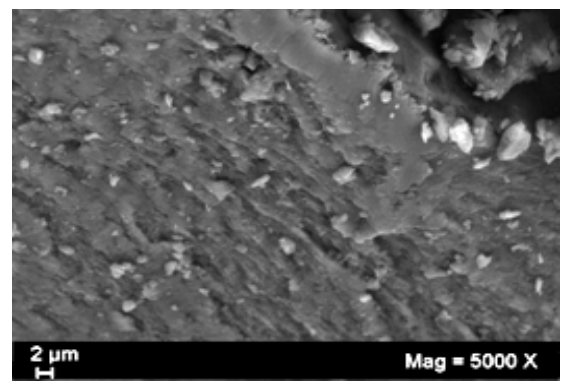

a

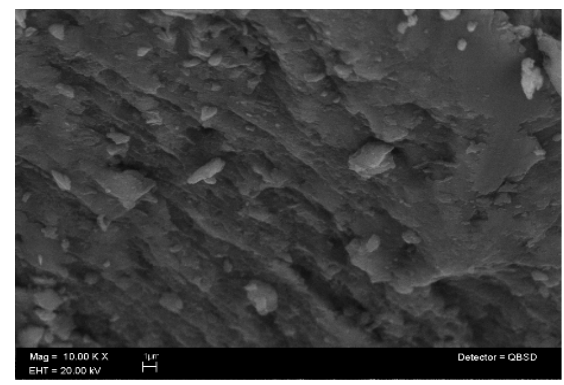

b

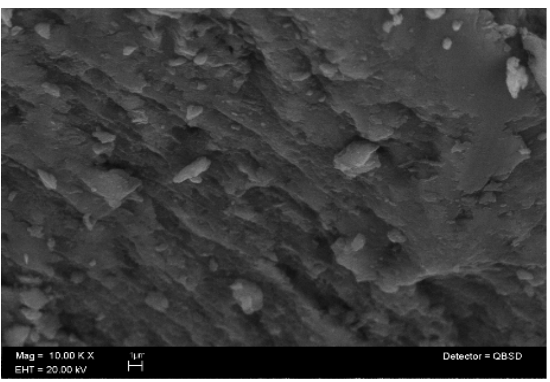

c

Fig. (3). Scanning electron micrograph of the H-MW sample (synthesis in presence of hair). a) x5000; b) x10000; c) x20000.

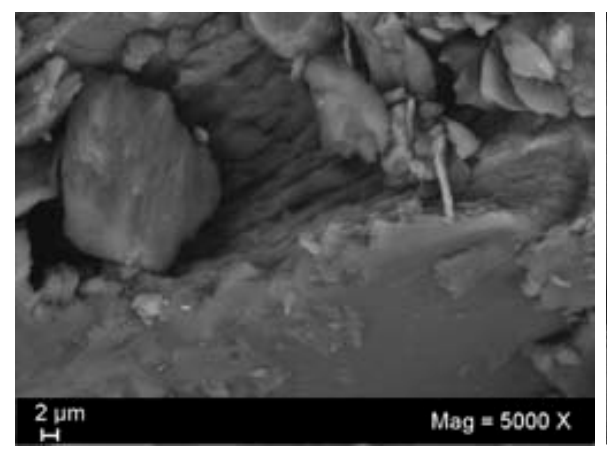

$\mathbf{a}$

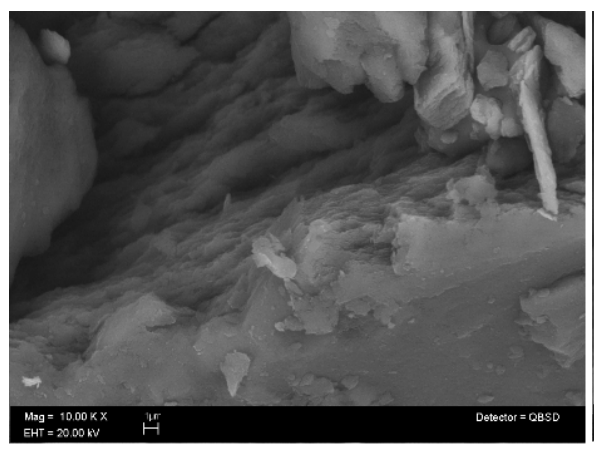

b

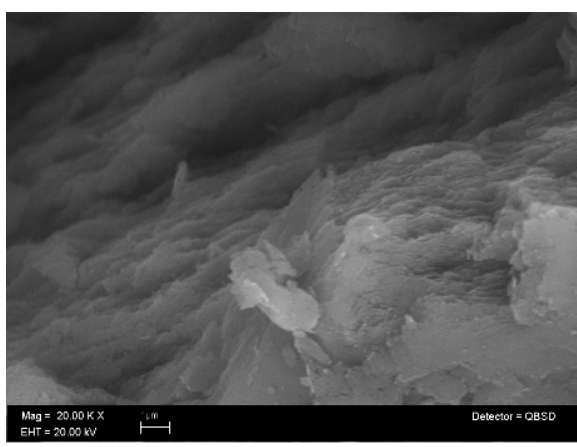

c

Fig. (4). Scanning electron micrograph of the hydrotalcite prepared in presence of cotton, C-MW. a) x5000; b) x10000; c) x20000. 


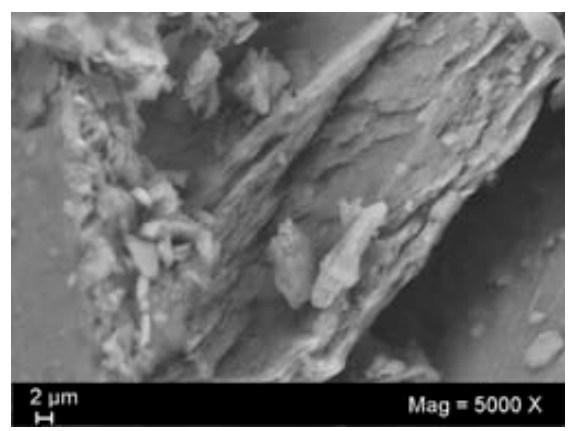

$\mathbf{a}$

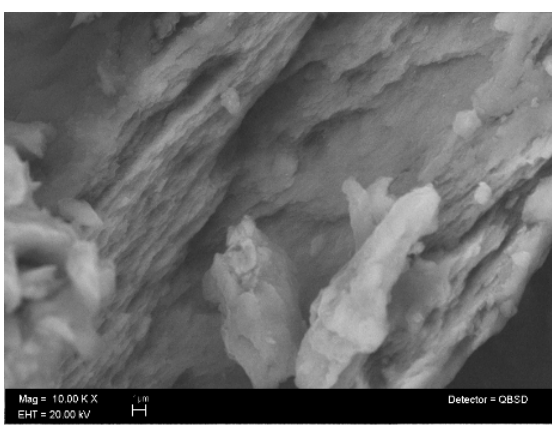

b

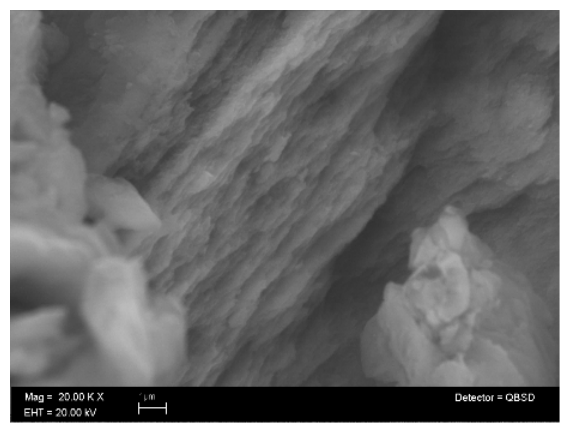

c

Fig. (5). Scanning electron micrograph of the sample prepared in presence of nylon, N-MW. a) x5000; b) x10000; c) x20000.

20 to $150 \AA$ with maxima, in C-MW at $100 \AA$ and, in N-MW at $70 \AA$. It seems, then, that the template size, as well as the hydrophobicity, determines the pore size distributions as hair is much larger $(70-90 \mu \mathrm{m})$ than nylon or cotton $(10-20 \mu \mathrm{m})$ which only differ in their hydrophobicity.

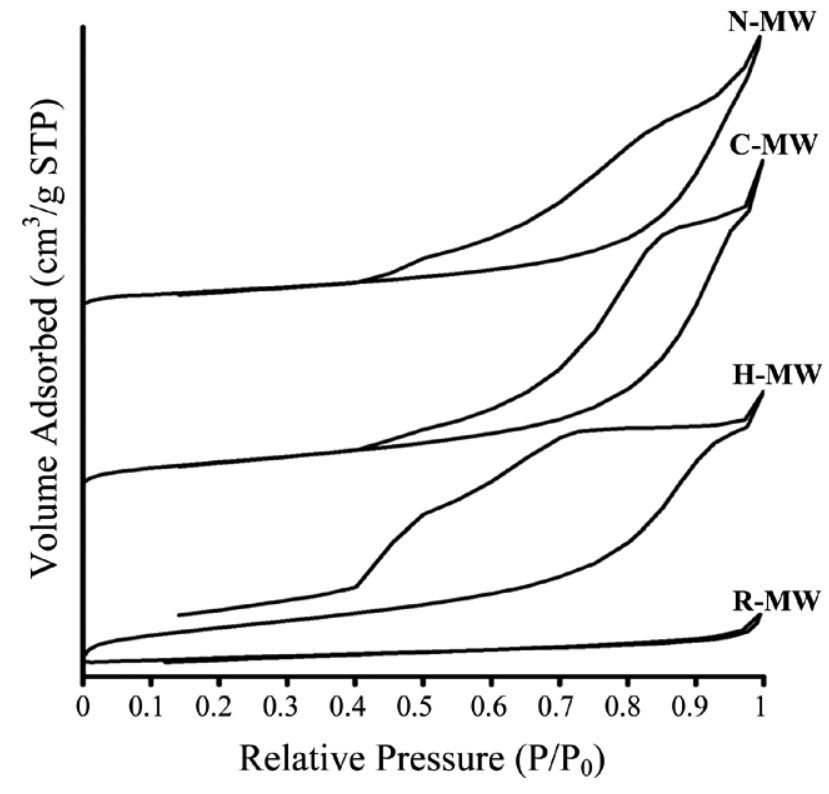

Fig. (6). Nitrogen adsorption-desorption isotherms of the samples.

\section{DISCUSSION}

Three hydrotalcites have been prepared with similar structure as shown by X-ray diffraction, but with different textural and morphological features depending on the size and hydrophobicity of the fibrous template. They were all prepared at a $\mathrm{pH}$ value of 8 , which ensures the integrity of the fibrillar inductors. Use of hair as a template is not new, as it has been used to prepare mesoporous silica tubes [21]. The authors report that not only a tubular morphology is obtained at a micron scale but also a nanometrical mesophase. The assembly of silica tetrahedra is very easily accomplished as the angle between tetrahedra may cover a broad range, from 180 to $60^{\circ}$. Instead, the magnesium or aluminum octahedra of hydrotalcite tend to form rigid layers.
In our sample, only the mesophase is obtained. In the micrographs, a longitudinal order of the hydrotalcite particles is observed. Hair is a low hydrophobic material whose surface may be fully covered by water molecules which, in

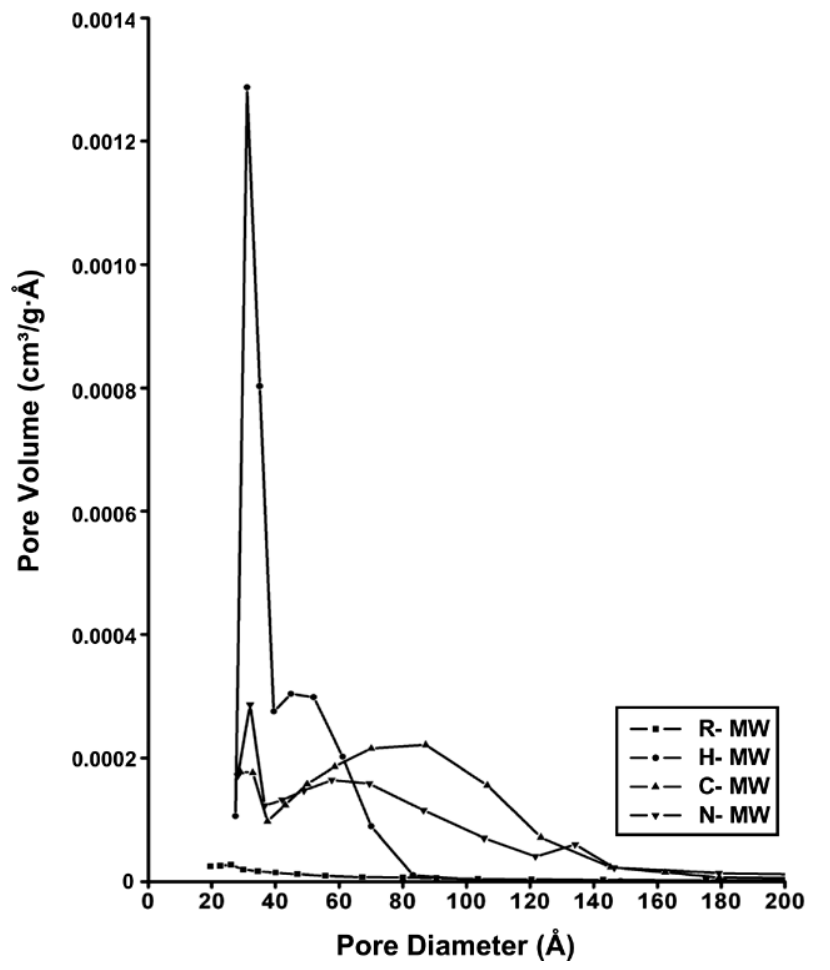

Fig. (7). Pore size distributions of the samples obtained by the BJH method.

turn, promote a high concentration of hydrotalcite precursors. The hair scale borders are probably nucleation centers, as they are covered by acid chains, which, in a basic medium, become negatively charged. The magnesium and aluminum cations are thus attracted, following parallel lines to the scale border. Indeed, they are separated $c a .4 \mu \mathrm{m}$, which is the distance between scales. It seems then that rings of hydrotalcite are formed all around the hair template. Micro- 
wave irradiation favors the formation of a large number of hydrotalcite seeds all around the scale border.

Such hypothesis is consistent with the results obtained with C-MW and N-MW samples, which do not present such ordered morphology. These two fibers have a lower diameter and therefore the surface is more curved. The adhered $\mathrm{Mg}, \mathrm{Al}$ octahedra, thus, cannot adhere to such a curved surface. Furthermore, there are no nucleation centers as these templates have no scales. Precursors, then, form the rigid layers observed in both samples. Such is not the case if alumina is synthesized, as biomorphic $\mathrm{Al}_{2} \mathrm{O}_{3}$ fibers have been prepared using natural fibers of cotton as bio-templates [22].

A second mechanism could be the one proposed by Carmody et al. [23]. Cotton fiber has at its surface a complex mixture of molecules made from carbon and hydrogen with a significant proportion of non-polar groups present. These non-polar groups have low surface energy and would be attracted to the oil molecules, but would repel our hydrotalcite aqueous precursors. Therefore, this should cause the formation of droplets in our sample. With temperature, small independent hydrotalcite particles are formed which are weakly bonded to the fiber. The use of microwave irradiation, of course, favors the formation of very small and hot droplets which result in well structured hydrotalcite small particles.

These trends are confirmed by the specific surface area values. Hair provides smaller particles and therefore a higher specific surface area. Only in this sample, pores close to 30 $\AA$ diameter are determined; this porosity is probably due to the assemblage of the hydrotalcite particles forming rings around hair. Instead, in the other two materials, specific surface areas are smaller, as hydrotalcite particles are large and well structured. The corresponding pore size distributions follow the same trend, only large pores are observed and they are due to interparticle spaces. The small values of specific surface areas are due to the well known blocking role of nitrates, as discussed in previous publications [24-26]. The differences in gibbsite amount in each sample can be correlated to the differences in $\mathrm{OH}$ surface content of the three templates. The hydrotalcite contains more aluminum in the low containing gibbsite samples.

\section{CONCLUSION}

The comparison among the hydrotalcites prepared using various organic fibrillar templates (hair, cotton or nylon) has shown that the interactions between the template and the hydrotalcite precursors determine the hydrotalcite morphology and texture. The hydrotalcite particle association forming rings around the fibrillar template or flakes weakly retained to cotton or nylon depends on hydrophobicity, as well as on roughness and surface curvature. Last but not least, microwave irradiation preparation technique is a simple and fast method to obtain these materials. It guarantees a high number of nucleation centers.

\section{ACKNOWLEDGEMENTS}

The authors acknowledge the financial support of CONACYT. The technical work in X-ray diffraction and electron microscopy of Leticia Baños and Omar Novelo is gratefully recognized.

\section{REFERENCES}

[1] Cavani, F.; Trifirò, F.; Vaccari, A. Hydrotalcite-type anionic clays: preparation. Properties and applications. Catal., Today, 1991, 11, 173-301.

[2] Sels, B.F.; De Vos, D.E.; Jacobs, P.A. Hydrotalcite-like anionic clays in catalytic organic reactions. Catal. Ver., 2001, 43, 443-488.

[3] Li, F.; Duan, X. Applications of layered double hydroxides. Struct. Bond., 2006, 119, 193-223.

[4] Tichit, D.; Vaccari, A. Recent catalytic applications of hydrotalcitetype anionic clays. Appl. Clay Sci., 1998,13, 311-326.

[5] Rives, V.; Ulibarri, M.A. Layered double hydroxides (LDH) intercalated with metal coordination compounds and oxometalates. $\mathrm{Co}$ ord. Chem. Rev., 1999,181, 61-120.

[6] He, J.; Wei, M.; Li, B.; Kang, Y.; Evans, D.G.; Duan, X. Preparation of layered double hydroxides. Struct. Bond., 2006, 119, 89119.

[7] Evans, D.G.; Slade, R.C.T. Structural aspects of layered double hydroxides. Struct. Bond., 2006, 119, 1-87.

[8] Malherbe, F.; Forano, C.; Besse, J-P. Use of organic media to modify the surface and porosity properties of hydrotalcite-like compouds. Microporous Mater., 1997, 10, 67-84.

[9] Valente, J.S.; Cantú, M.S.; Cortez, J.G.H.; Montiel, R.; Bokhimi, X.; López-Salinas E.J. Preparation and characterization of sol-gel $\mathrm{MgAl}$ hydrotalcites with nanocapsular morphology. Phys. Chem. C., 2007, 111, 642-651.

[10] Choy, J-H.; Kwak, S-Y.; Jeong, Y-J.; Park, J-S. Inorganic layered double hydroxides as nonviral vectors. Chem. Int. Ed., 2000, 39, 4041-4045.

[11] Lima, E.; Bosch, P.; Loera, S.; Ibarra I.A.; Laguna, H.; Lara, V.H. Appl. Clay Sci., 2009, 42, 478-482.

[12] Giannelis, E.P. Polymer layered silicate nanocomposites. Adv. Mater., 1996, 8, 29-35.

[13] Fetter, G.; Hernández, F.; Maubert, A.M.; Lara V.H.; Bosch, P. Microwave irradiation effect on hydrotalcites synthesis. J. Porous Mater., 1997, 4, 27-30.

[14] Tichit, D.; Rolland, A.; Prinetto, F.; Fetter, G.; Martínez-Ortíz, M.J.; Valenzuela, M.A.; Bosch, P. Comparison of the structural and acid-base properties of Ga- and Al-containing layered double hydroxides obtained by microwave irradiation and conventional ageing of the synthesis gels. J. Mater. Chem., 2002, 12, 3832-3838.

[15] Rivera, J.A.; Fetter, G.; Bosch, P. Microwave power effect on hydrotalcite synthesis. Microporous Mesoporous Mater., 2006, 89 , 306-314.

[16] Benito, P.; Labajos, F.M.; Rocha, J.; Rives, V. Influence of microwave radiation on the textural properties of layered double hydroxides. Microporous Mesoporous Mater., 2006, 94, 148-158.

[17] Bergadà, O.; Vicente, I.; Salagre, P.; Cesteros, Y.; Medina, F.; Sueiras, J.E. Microwave effect during aging on the porosity and basic properties of hydrotalcites. Microporous Mesoporous Mater., 2007, 101, 363-373.

[18] Lopez, T.; Bosch, P.; Asomoza, M.; Gomez, R.; Ramos, E. DTATGA and FTIR spectroscopies of sol-gel hydrotalcites: aluminium source effect on physicochemical properties. Mater. Lett., 1997, 3, 311-316.

[19] Rivera, J.A; Fetter, G.; Jiménez, Y.; Xochipa, M.M.; Bosch, P. Nickel distribution in (Ni,Mg)/Al-layered double hydroxides. Appl. Catal. A, 2007, 316, 207-211.

[20] Lodge, R.A.; Bhushan, B J. Surface characterization of human hair using tapping mode atomic force microscopy and measurement of conditioner thickness distribution. Vacuum Sci. Tech. A, 2006, 24, 1258-1269.

[21] Li, N.; Li, X.; Wang, W.; Qiu, S. Mesoporous silica tubes fabricated with human hair as template. Mater. Chem. Phys., 2005, 91, 223-226.

[22] Fan, T.; Sun, B.; Gu, J.; Zhang, D.; Lau, L.W.M. Biomorphic $\mathrm{Al}_{2} \mathrm{O}_{3}$ fibers synthesized using cotton as bio-templates. Scripta Mater., 2005, 53, 893-897.

[23] Carmody, O.; Frost, R.; Xi, Y.; Kokot, S. Surface characterisation of selected sorbent materials for common hydrocarbon fuels. Surface Sci., 2007, 601, 2066-2076.

[24] Fetter, G.; Olguín, M.T.; Bosch, P.; Bulbulian, S. Surface areas of nitrated hydrotalcites. J. Porous Mater., 2000, 7, 469-473.

[25] Olanrewaju, J.; Newalkar, B.L.; Mancino, C.; Komarneni, S. Simplified synthesis of nitrate form of layered double hydroxide. $M a$ ter. Lett., 2000, 45, 307-310. 
[26] Naghash, A.R.; Xu, Z.; Etsell, T.H. Coprecipitation of nickelcopper-aluminum takovite as catalyst precursors for simultaneous production of carbon nanofibers and hydrogen. Chem. Mater., 2005, $17,815-821$.

(C) Sommer et al.; Licensee Bentham Open.

This is an open access article licensed under the terms of the Creative Commons Attribution Non-Commercial License (http://creativecommons.org/licenses/ by-nc/3.0/) which permits unrestricted, non-commercial use, distribution and reproduction in any medium, provided the work is properly cited. 